\title{
Open Education and Open Educational Resources for the Teaching of Classics in the UK
}

\author{
Simon Mahony
}

University College London

\begin{abstract}
New technologies have always introduced new possibilities but these invariably bring fresh problems with them. The expansion and wider availability of digitised teaching content is no exception and there are now new affordances but as a result new questions need to be asked about our teaching practice. Academics within the same departments have always shared teaching materials but a cultural change is taking place in universities, with academics using the internet to share their research (Open Access) and teaching and learning resources (OER: Open Educational Resources) more widely. This chapter draws on the experience of completed Jisc and the Higher Education Academy funded projects for the creation, use, and importantly reuse of OERs. These themes are developed, drawing on the experiences of the Digital Classicist, the Stoa Consortium and other open initiatives in Classical Studies, such as OpenLearn at the Open University, and so situating these ideas within the sphere of the teaching of Classics. As part of this research a systematic search for Classics teaching material was conducted in the major UK repositories and beyond, revealing a paucity in discrete classroom based learning objects, hence raising more questions. This chapter also makes suggestions for best practice in the production of OERs and calls for the establishment of recognised standards.
\end{abstract}

\section{How to cite this book chapter:}

Mahony, S. 2016. Open Education and Open Educational Resources for the Teaching of Classics in the UK. In: Bodard, G \& Romanello, M (eds.) Digital Classics Outside the Echo-Chamber: Teaching, Knowledge Exchange \& Public Engagement, Pp. 33-50. London: Ubiquity Press. DOI: http://dx.doi.org/10.5334/ bat.c. License: CC-BY 4.0. 


\section{Introduction}

New technologies have always introduced new possibilities but these invariably bring fresh problems with them. The expansion and wider availability of digitised teaching content is no exception in that there are now new affordances but as a result new questions that need to be asked about our practice as educators. It is true that academics within university departments have always shared teaching materials; a new staff member will generally take over existing established and perhaps core modules as well as developing new ones based on their research interests. However, over the last decade, a cultural change appears to have been taking place enabled by the internet and digital content whereby academics now share their research (Open Access) and teaching and learning resources (Open Educational Resources: OERs) much more widely. This spirit of collaborative working appears to be increasing, and, it is argued here, has the potential to open up higher education, giving both students and teachers greater access and flexibility and at the same time help to break down the institutional barriers between research and teaching.

This chapter draws on the experience and outputs of completed Jisc and the Higher Education Academy (HEA) ${ }^{1}$ funded projects for the creation, use, and importantly reuse of OERs. Firstly, VirtualDutch (www.dutch.ac.uk), part of the Open Learning Environment for Early Modern Low Countries History where a lesser taught language subject community have collaborated in joint teaching projects and developed a wide range of resources. ${ }^{2}$ The second is Digital Humanities Open Educational Resources which was set up to create and release a comprehensive range of introductory materials on approaches, topics and methods in the Digital Humanities. ${ }^{3}$ A third project, CPD4HE: Open Resources on HE Teaching and Learning, is also included as it has direct relevance to the argument presented here. These themes are developed, drawing on the experiences of the Digital Classicist, the Stoa Consortium and other open initiatives in Classical Studies, such as OpenLearn at the Open University $(\mathrm{OU})$ and so situating these ideas within the sphere of the teaching of Classics. ${ }^{4}$

This chapter does not argue for the transformative possibilities of Open Education or OERs and how they might shift the balance between teaching and learning at a time when educators are stretched by ever mounting demands. ${ }^{5}$ Rather, my direct involvement in the OER movement and pedagogy combined with a background in Classics prompted a survey of the open teaching materials available for Classics in the Anglophone world. Following this, the major question that arises is that although there are many exemplary resources within the field of Classics (and Digital Classics in particular) that are suitable to support teaching and also that Classicists have always been at the forefront of new technological developments, why is there a lack of fine grained classroom based 'learning objects' for the teaching of Classics? ${ }^{6}$ The argument presented here is that to become used more extensively these resources need to become part of the routine tool kit of educators and that before they can be successfully used 
they first need to be found. Suggestions for best practice are offered based on the experience of the OER projects mentioned above and a call is made for the establishment of recognised standards and metadata.

\section{Open Education and Open Educational Resources at UCL}

2010 saw the launch of the UCL Centre for Digital Humanities (UCLDH) and in the following year the new Master's programme enrolled its first cohort of students. UCLDH is a research centre and as such has output in the form of projects and publications but the Master's programme also allows for the integration of research and teaching and thus facilitating research and publishing on teaching itself. ${ }^{7}$ Becoming involved in the OER movement has allowed all three of these activities to be pursued. ${ }^{8}$

The projects named in the introductory section consider that the true rationale of openness to be one of reclaiming original academic practice and collaboration.

Open access stands for unrestricted access and unrestricted reuse. Paying for access to content makes sense in the world of print publishing, where providing content to each new reader requires the production of an additional copy, but online it makes much less sense to charge for content when it is possible to provide access to all readers anywhere in the world (Public Library of Science). ${ }^{9}$

We can trace the origins of the global OER movement back to the UNESCO Conference of 2000 where it is important to remember what the initials stand for in the well-used and perhaps over-familiar acronym (the United Nations Educational, Scientific and Cultural Organization).

Open Educational Resources are teaching, learning or research materials that are in the public domain or released with an intellectual property license that allows for free use, adaptation, and distribution. ${ }^{10}$

The movement gained momentum with the launch of MIT OpenCourseWare in 2001 and the founding of Creative Commons with their first licences released in the following year. However, this chapter is not going to give a history of the OA or OER movements as that is widely available elsewhere, nor is it going to argue for their importance but take it as a given. ${ }^{11}$ The point here is that in essence the move towards openness has been with us for some time but our approach within education and the development of educational resources should always be new and changing to remain innovative and be part of an increase in the overall culture of Open Access moving away from paywalls and subscription sites. 
At the simplest level, and in the context of this chapter, an OER may be just a lecture presentation, a reading list, some class-based task or exercise, topics for seminar discussions or even exam questions. On a broader level they may also include 'full courses, course materials, modules, textbooks, streaming videos, tests, software, and any other tools, materials, or techniques used to support access to knowledge. ${ }^{\text {' }}$

One issue that is currently unresolved and stimulating debate within the movement is that OERs still continue to be relatively unused in most education programmes. There may be many reasons for this: a general lack of awareness of OERs, especially at the more traditional higher education institutions; an unwillingness to use other people's material for teaching; a belief that by releasing the material and making it freely available there is, in some way, a loss of ownership; or it may simply be a reluctance to give away ones precious teaching material for free. There also may be institutional issues; for example the 'employer' (i.e. university) may claim copyright on the employees work and will not allow it to be freely distributed and hence effectively banning the release of OERs. This relative lack of use is an important issue but not one that will be explored in the context of this chapter other than as far as it concerns discoverability; although freely and openly available, it seems clear that OERs will only be used if they are easily findable and also if their use has become part of the standard workflow of the educators. Overall, producing resources and releasing them as OERs is not enough; it is necessary for us to develop communities of practice around the use of re-usable learning objects and materials. In addition, and to facilitate this, the ongoing practice of developing Open Resources for teaching, needs to become part of the training (and professional development) of teachers at all levels; this is the importance of the following project and how it fits into the overall argument presented here.

\subsection{Open Resources on HE Teaching and Learning}

CPD4HE (Continuing Professional Development for Higher Education), funded by the UK Higher Education Academy and Jisc, ${ }^{13}$ was developed to release educational resources to support the professional development of lecturers and teaching staff at UCL (and being released as OERs, to do so more widely). In all UK higher education institutions, probationary teachers and lecturers are required to attend and participate in training programmes (it is also recommended for the continuing professional development of all teaching staff). This is where the creation, release, use and re-use of teaching materials can be instilled in up-and-coming educators. When these methodologies become commonplace in the teaching of educators and the development of their research practice, they will similarly become more commonplace in the arsenal of teaching tools employed by course and module tutors. This is important for building a community of practice around OER release 
and re-use at an institutional level. Moreover, following the completion of this and the two projects that follow, discussions have been held in consultation with UCL Libraries about the feasibility of setting up an institutional repository for OERs. This is not because we need another OER repository as we already have, inter alia, Jorum and HumBox, ${ }^{14}$ but rather to make the creation and release of OERs part of normal institutional practice and the workflow of teaching staff just as institutional repositories are now mandated for staff research output. These discussions are, at the time of writing, still ongoing but the move towards such a repository is now acknowledged on the institutional domain. ${ }^{15}$ The two other relevant projects are briefly outlined here.

\subsection{Open Learning Environment for Early Modern Low Countries History}

This was a joint project to bring together teaching materials to support a lesser taught subject community: Dutch studies. ${ }^{16}$ Modern foreign languages are recognised by the Higher Education Funding Council for England (HEFCE) as being a 'strategically important and vulnerable subject' area. ${ }^{17}$ Dutch is a minority subject despite, arguably, being the European language closest to English and widely taught across the continent. The general decline in teaching modern languages affects all language programmes but is particularly pertinent for those not widely taught. ${ }^{18}$ This project resulted in the collaboration between the four institutions in England that teach Dutch at university level (UCL, Sheffield, Cambridge and Nottingham) to develop and release open teaching materials. This allowed cooperation and the sharing of resources to bring more breadth to the curriculum which has been of direct benefit to students and staff at the participating partner institutions. ${ }^{19}$ The relevance here is that the decline in learning languages is not restricted to modern ones but to ancient ones too; in addition, combining resources freely, strengthens rather than weakens the subject area. This is a model that could be adopted for strengthening the teaching of Classical languages and particularly by developing and sharing classroom based resources.

\subsection{Digital Humanities Open Educational Resources (DHOER $)^{20}$}

DHOER created sharable teaching resources taken from the Digital Humanities Master's programme at UCLs Department of Information Studies and made them freely and widely available via HumBox and Jorum. Importantly, these resources go beyond the Digital Humanities sphere and are intended to support many cognate disciplines, including the whole spectrum of the arts and humanities (potentially Classics too), cultural heritage, information studies and library studies. At an early stage the decision was taken (based on 
the experience of VirtualDutch) that to facilitate the use and re-use of these resources they must not only be open to use in other disciplinary areas but also be released in an open format that allows for their use, adaption and re-use. The standard format for text or graphic based OERs seems to be PDF as these can be opened simply in a browser and handled by almost every platform and end user (including those not comfortable with technology); however, these are of course not 'open' and as such contradict the earlier statements on openness. To resolve this, as well as being released as individual PDFs, resources from this project were also bundled together by module together with the original source files in Open Document Format (ODF) to facilitate reuse, editing and extending the original material. Importantly, these are made available together with instructions and links to Open Source office suites; metadata and licensing details are included as well as how the folders might be unpacked and ODF made use of. Particularly important are details about the assumed level and how and where individual OERs might fit within a programme. Rather than a single large resource, the focus of this project shifted towards the creation of smaller units of learning objects which might be used strategically where needed. This together with the open format, metadata for context, level and discovery should be essential parts of any OER output.

\section{Open Educational Resources for Classics in the $\mathrm{UK}$ and beyond}

The resources released by the projects briefly outlined above, as well as being archived institutionally, have been uploaded to the two main UK repositories for OERs, Jorum and HumBox. As part of the research for this chapter a systematic search was conducted for teaching material for Classics in both these (and other) repositories.

A keyword search for 'classics' in Jorum (all the results that follow are at the time of writing) returns 67 hits; the top ones offer resources on 'information management' and 'essay writing' with some further down the list on Greek drama followed by World War I. By far the most hits are to resources for English grammar which is laudable but they are not 'classics. ${ }^{21}$ Searching 'classical studies' returns 14 hits with little relevance for us here except 'Podcasting the Ancient World' which offers a broken link to that resource. Searching using 'Latin' as keyword brings nothing relevant and 'Greek' returns, amongst many irrelevant hits, 'Greek Drama' and again the broken link to 'Podcasting the Ancient World.'

A similar search for 'classics' on HumBox returns 66 different results but not until hit 29 do we find anything relevant: a collection titled 'Views in Greece from drawings by Edward Dodwell. A collection of drawings of views in Greece by the English traveller and archaeologist Edward Dodwell (1776/7-1832).22 'Classical studies' returns 12 hits; the results of this search are rather curious 
as the first one is a presentation on 'Open Source and Open Access' (by one of the editors of this volume) which forms part of the DHOER collection and the second by a former colleague who at the time worked at the English Language Subject Centre and both resources were part of the Jisc/HEA OER Phase 2. This is particularly interesting as neither are tagged 'classical studies', 'classics' or 'studies' nor do they contain that as a character string anywhere in the document content. ${ }^{23}$ This does raise pertinent questions about the search algorithms used by this resource. When uploading content, authors are asked to select an appropriate Creative Commons licence, and add keyword 'tags' and a brief description; this is supplemented with automatically generated upload metadata such as 'creators' and 'date added.' There is no clear reason why those two resources should come at the top of the list for a search using 'Classical studies' as a search term. ${ }^{24}$ Searching 'Latin' and 'Ancient Greek' have similar disappointing results. It is notable then that there is clearly a paucity of OERs for Classics in the two major national repositories of classroom based teaching and learning materials.

It is important to remember that the granular approach of the individual learning object is, of course, not the only methodology for open education as can be seen with the broad based approach of MIT and the increasing number of MOOCs. ${ }^{25}$ There is of course a fundamental difference between the two: MIT OpenCourseWare (MIT OCW) offers 'off the shelf' courses for delivery whereas, for example, a Coursera MOOC asks students to sign up and follow a specified programme of study. ${ }^{26}$ Both are very different from each other and from the discrete learning objects anticipated by an OER.

Conducting similar keyword searches on MIT OCW ('a web-based publication of virtually all MIT course content') and Coursera ('Take the world's best courses, online, for free') give interesting results. ${ }^{27}$ Using 'classics' as a search term in the former returns 63 results which are mainly courses on 'Classics' of Chinese and American literature; in Coursera it returns 3: a course on 'Historical Fiction' and two hits for the same course on the 'Chinese Humanities. ${ }^{28}$ 'Classical Studies' returns no results on Coursera and 58 on MIT OCW: the first being 'Classical Literature: The Golden Age of Augustan Rome' followed by (classical) Music, Engineering and Physics (classical mechanics). As might be anticipated 'Latin' returns hits on both (42 on MIT OCW and 4 on Coursera) with almost all being concerned with 'Latin American' studies. ${ }^{29}$ 'Ancient Greek' returns 13 hits on MIT OCW and 2 on Coursera. ${ }^{30}$

For completeness, it needs to be clear that the above are not the only platforms for the discovery of Open Education materials. Udacity ('Advance your career') focuses on technical courses, mainly programming and Computer Science, and seems to be designed to enhance users' skills portfolio; hence nothing for classics there. ${ }^{31}$ edX ('great online courses from the world's best universities'), founded by Harvard \& MITx (now includes Berkeley and other partners) and unlike Coursera claim to be a collaborative, non-profit 
organisation, operating on an Open Source platform..$^{32}$ Course selection here is by a subject specific dropdown menu with no text-box search interface. Scrolling through 'History' in 'all schools' (39 results) finds 'The Ancient Greek Hero in 24 Hours (Hours 1-5): Epic and Lyric' (a cut down taster for what follows), 'The Ancient Greek Hero' (a 17 week course with no prerequisites) and 'Was Alexander Great? The Life, Leadership, and Legacies of History's Greatest Warrior' (a 13 week course with no pre-requisites). Again, these necessitate enrolling and following a prescribed course.

A UK based MOOC platform owned by the Open University, FutureLearn ('Connecting people and ideas. The best free online courses in the world'), has a long list of partner institutions, mostly in the UK. ${ }^{33}$ Again there is no global search function and courses are available in a list with an image, strapline, start date and duration together with the number of hours per week that are expected from students. For our purposes, the only relevant course in 'New \& upcoming' seems to be 'Hadrian's Wall: Life on the Roman Frontier' offered by the University of Newcastle (6 weeks at 4 hours per week). One of the partner institutions is the University of Southampton and looking though their 'past' courses finds: 'Archaeology of Portus: exploring the lost harbour of ancient Rome' (duration: 6 weeks, 2 hours per week). All these courses clearly display their start date, duration, hours per week and whether a certificate is available, together with an image; importantly, this information is displayed in the list itself without having to open the course page to find the necessary details. Once registered, a simple click enrols you on the course with email alerts to prompt progress and discussion in the appropriate fora. It is clear from the lack of a search box in both these platforms that, rather than relying on natural language searching for content discovery, they use an index of keyword metadata system to allow faceted browsing.

\section{Widening the search}

It seems then that although there are many well known and high profile online digital resources for Classics (and many support teaching), there is little, if anything, in the way of discrete learning based objects that would match the OER criteria. Following this survey and to address this overall lack of granular teaching resources, a new page on the Digital Classicist wiki was launched in late 2013 to gather together Digital Humanities type educational resources and OERs for Classics and further research was undertaken by this author. ${ }^{34}$ Adopting a community approach, the various Classics-related Jiscmail lists were circulated as well as popular social media channels such as Classics International (on Facebook) and Twitter with a request for any relevant material.

Close to home, the head of the Classics department at the Open University (OU) responded to the email looking for open teaching resources which prompted further investigation of OpenLearn ('The home of free learning from 
the Open University'). ${ }^{35}$ Searching for 'Classics' required scrolling to the second page of hits (default of 10 per page) to discover relevant courses such as Greek tragedy ('A reader's guide to Medea' and 'Oedipus: The message in the myth') and Classical Latin. 'Classical Studies' returns more results with links to Classical Latin, reception studies, and history on the first page. Employing a different search strategy and using the menu with drop down options (to allow a faceted rather than a natural language search), 'History \& The Arts' > 'History' > 'Classical Studies' gives more fruitful results: 'Most popular from Classical Studies' from where you can scroll down to a more visually appealing and informative selection with images, brief description of each course and the essential metadata. Included in the metadata for many is the 'Duration' from which the user can clearly determine if this is a taster course ('Getting started on Classical Latin': Introductory level, Duration 10 hours) or something more substantial ('Certificate of Higher Education Open': Duration 1200 hours) and importantly, where appropriate, the level (introductory, intermediate etc.). Again, although these courses are free, vary in duration and level, they are still ones that you sign up for and follow as a student.

What are less easy to find at the OU are the many excellent resources not on OpenLearn but offered by the Classics department itself, particularly taster materials for 'Classical Studies' and the 'Ancient Olympics', and those for language learning more generally, which are freely available under Creative Commons licences. Following the thread: 'Open University' > 'Department of Classical Studies' > 'Taster Material' takes you to 'Taster Materials for Classical Studies' that include podcasts, videos, short essays and sample course materials. ${ }^{36}$ For example, links to 'Getting Started on Classical Latin' and 'Continuing Classical Latin' both with Creative Commons BY-NC-SA ${ }^{37}$ licences attached with a link to a page clearly defining and making clear what may be done with this material. Having rights and permissions clearly stipulated and spelled out in clear sight is an essential part in getting materials used and re-purposed.

There are of course other alternatives for finding Open Educational Resources. Xpert (Xerte Public E-learning ReposiTory), hosted at the University of Nottingham, is a Jisc funded search engine specifically built to 'to explore the potential of delivering and supporting a distributed repository of e-learning resources. ${ }^{38}$ This project aims to allow a search interface to specifically identify and retrieve OERs. Using 'Classics' as a search term retrieves 366 results with reassuringly some coming from the $\mathrm{OU}$ on the first page. However, the results are not universal as testing with searches for DHOER (and other topic related tags used on the DHOER project) return no results. ${ }^{39}$ The author contacted the technical developers at Xpert who could not account for this anomaly as their search metadata is allegedly harvested directly from Jorum and the other repositories. What it does return (again on the first page) are links to the Oxford University Podcasts. ${ }^{40}$ These feature video recordings of various talks on a variety of topics such as Classics, Roman Comedy, and Classical Literature; most 
are from the Jisc/HEA OER phase 1 strand and almost all have Creative Commons licences clearly and prominently attached.

The results of the desk-top survey conducted as part of this research show that the availability of class-based teaching OERs in the area of Classics are very limited; those found using anticipated search methods, at present, consist of classical subject paintings in HumBox, podcasts from the University of Oxford (both these developed as part of the HEA/Jisc funding initiatives) and resources that can be extracted (licence allowing) from materials made available by the Classics Department at the Open University.

Some other resources that are important to mention can be found on the Stoa Consortium pages. The Stoa serves as the official blog of the Digital Classicist community but also hosts a wide range of resources with a continuing commitment to Open Access and networked scholarship being fundamental principles. ${ }^{41}$ Many of these are legacy sites but others such as 'Suda on line' ${ }^{\text {' }}$ and 'EpiDoc guidelines' ${ }^{\text {'3 }}$ are very much current.

Various open image collections are also available online to support teaching and research in Classics. As well as those on the Stoa, the Ancient World Image Bank, started at the Institute for the Study of the Ancient World, 'is a collaborative effort to distribute and encourage the sharing of free digital imagery. ${ }^{44}$ All images there are freely downloadable from their Flickr account and released with a simple Creative Commons Attribution (CC-BY) licence and so also meet the OER criteria. ${ }^{45}$

It is also important to remember that new resources are coming online all the time such as Perseids ('a collaborative editing platform for source documents in Classics'); ${ }^{46}$ Iliados ('grammatical and syntactical searches on the Perseus Treebank'); ${ }^{47}$ Alpheios ('reading tools for Latin, ancient Greek and Arabic'). ${ }^{48}$ These, along with other high profile resources for Classics, such as the Perseus Digital Library, Thesaurus Linguae Graecae, Duke Databank of Documentary Papyri, Inscriptions of Aphrodisias, Roman Tripolitania and Cyrenaica are all in their way excellent resources and serve to support teaching and research in a variety of different ways. However, they do not provide immediately usable and suitably packaged material to be incorporated in the lecture hall, seminar room or computer lab; that is not their purpose and it should not be expected of them. What is missing generally within this broad disciplinary area, are dedicated open teaching resources suitable for the teaching room, collections of copyright free teaching materials that the over-stretched and time-starved lecture or module tutor can turn to when putting together their teaching plan(s).

\section{Open Education in Context}

With regards to OERs more generally, it is essential to remember that making them accessible, free and online does not necessarily make them available to the people who would benefit from them the most. Once released online, they 
are indeed open to the world, but only to the 'well connected' world, which is expansive, but not universal. What are needed are not resources that look good on the latest smartphone or tablet device, but ones that display effectively on low-cost mobile phones and incorporate simple, widely used technologies. The most successful online teaching resources are not those that utilise technologies with the highest pedagogical qualities but rather those that make use of 'technologies which are generally available. ${ }^{49}$ Materials should be optimised for the lowest reasonably employable technology, rather than the highest, and producers should not assume that their users will necessarily have access to the same resources that they do.

Further, issues about context and ownership need to be addressed. As we have seen, MIT OpenCourseWare, for example, delivers complete courses and modules pre-packaged, off the shelf and ready to go. However, the user of Jorum or HumBox is generally looking for a task, exercise or learning object to complement a class or lecture, something to aid the students' understanding of what is being taught or indeed even for the students themselves to find and make use of themselves as self-learners. Firstly, the resource needs to be found: it must have adequate and relevant discovery metadata attached, rich enough to fully describe the content, but, at the same time, the metadata needs to be sufficiently focused to prevent the user being overwhelmed with irrelevant results. Once found, the individual OER may lack context which needs to be made explicit; where does it fit within a programme, module, teaching session or task-based learning exercise? This information also needs to be included at an object-based level along with the assumed level of the students' competence. What is the learning context? Who is the intended audience? These are essential questions that need to be addressed when producing OERs regardless of the disciplinary area, whether that be Classics or Digital Humanities.

Moreover, if the teaching that uses the OER is credit based, then there will be the need for assessment. This becomes a potential problem area unless the OER package contains sound pedagogical material that is moving towards that assessment. In addition, different cultures have different learning styles, attitudes to change, memory and aesthetic tastes. ${ }^{50}$ This goes far more deeply than the need for translation when adapting learning materials for another global area. This is also equally true of areas where English has become the 'lingua franca,' as the localization of content is still needed to compensate for cultural differences, particularly in the area of graphics, symbols, colours, layout and other variants. ${ }^{51}$

Once all this is taken care of, there still remains the often contentious question of ownership and the continuing relationship between the original author and the re-used and, perhaps, adapted OER. Considerable funding has gone into the creation of OERs and this will be in danger of being wasted without efforts being made to ensure their sustainability and this is where developing the community of practice becomes important. Making the creation and release of OERs part of the normal institutional workflow (which is the focus of the CPD4HE project) will help to ensure that sustainability. 
We do not yet have reliable metrics for the measurement of the use of OERs; we can gather download statistics simply enough but that is no indication of whether or not they have actually either been used as a teaching resource or re-purposed and adapted in some way. The long term hope of the OER community is that the teaching materials will be taken, used and improved, and then fed back into the repositories and so becoming an iterative cycle contributing to the growth of knowledge and knowledge production. The situation then approaches one that is analogous to peer review; errors, omissions, typos and broken links can be corrected and the resource returned with improvements and acknowledgement (if required by the licence). This methodology facilitates the equal partnership between research and teaching that is so often claimed but less often observed at the Higher Education level.

\section{Conclusions}

Within the field of Classics digital resources for teaching and (so-called) e-learning have been becoming more prominent on the agenda. Witness two panel sessions on 'New Approaches to eLearning in Classics' at the (UK) Classical Association Annual Conference at the University of Nottingham (2014), ${ }^{52}$ the 'iLatin and eGreek - Ancient Languages and New Technology' symposium hosted by the Open University (2014) ${ }^{53}$ and Hestia2 on 'Digital Pedagogy: How are new technologies transforming the interface between research and learning? ${ }^{54}$ The focus of each of these was teaching and the use of technology (in various forms) to support teaching; all were based on research conducted by the presenters and form solid exemplars of the synergy between teaching and research in the field of Classics.

The suggestions argued for here are those recommended by this author based on the experience of running an OER project and by extensive research within the area of Open Education and OERs. With Open Education and OERs specifically what is most important is that the resources should be easily found; they need appropriate discovery and relevant focused metadata. Once found, their place and purpose within an educationally robust curriculum needs to be clear along with an intellectual property licence allowing free use, re-use, adaption and distribution with attribution. The intended audience and level should be apparent. These should be (or have a version that is) in an open format with a low technical threshold. In the case of ancient languages, just as with other vulnerable subject areas, much advantage can be gained by joining together and sharing resources, as has been seen with VirtualDutch, to strengthen and develop the curricula of collaborating departments.

It is unfortunate that despite three rounds of research funding within the UK (specifically to promote usage by encouraging the incorporation of OERs into all government sponsored education), extensive government and private 
funding in the USA, an Annual Open Education Conference, as well as a dedicated annual OER Conference, ${ }^{55}$ there are not yet recognised standards for metadata or best practice. Following the end of the funding period the Jisc pages on Open Education appear to have been archived at the end of January 2013. ${ }^{56}$ The closest that can (to date) be found is The Open Education Handbook: '[...] a collaboratively written living web document targeting educational practitioners and the education community at large. ${ }^{37}$ This was (and still is) a community effort and part of the European based LinkedUp Project, kick-started by a series of booksprints, the first of which was held in London and participated in by this author. ${ }^{58}$ The handbook pulls together much useful information about Open Education and Open Educational Resources along with finding and using Open Data for education but stops short at advocating any specific standards or metadata schemas.

As far as Classics is concerned we have this anomaly of the seeming lack of fine grained openly available teaching resources. Many innovative and high profile online Classics projects are in evidence and many indeed may be used to support teaching. However, there is a clear dearth of classroom based teaching material ('learning objects') and it is unclear why that is the case. This lack may be connected in some way to the general pedagogical concerns within the teaching of Classics, and as such is outside of the scope of this investigation, and would be a useful focus for a follow up study. An alternative possibility is that they are simply very difficult to find as they are missing the appropriate discovery metadata and hence there would be a lack of awareness of their existence; this scenario would be addressed by following the suggestions for best practice put forward in this chapter and the establishment of recognised standards and metadata.

The methodology for the research on which this chapter is based is admittedly limited in that it examines only the English speaking material. The mailing lists used to contact the Classics communities are indeed international but responses to the requests for guidance towards resources only came from within the UK and the USA. This may introduce a bias but all the same in the context of teaching Classics in the Anglophone world such resources are clearly missing. Despite this it would be useful to have other perspectives from the non-Anglo international Classics community; this would allow a useful comparison (i.e. is this lack specific to the English speaking Classics community or a more general one in the teaching of Classics).

Nevertheless whatever the cause, Open Educational Resources are (or should be) pedagogically driven as should all teaching resources. The discussion around this whole area of Open Education, the creation, release, use and re-use of OERs more generally, granular versus a broad based approach, does have one significant spin-off benefit whether within the field of Classics or elsewhere. It encourages us as educators and researchers involved in teaching to talk about and reflect on our teaching practice and how indeed teaching and research are interlinked. 
Whether they are used or not, OERs (and Open Education more generally) have stimulated the discussion on, and research into, the learning process and our pedagogical aims. They have become the agents of change and objects to talk about, giving us the opportunity to interrogate what we do as educators. There is not one single solution or approach and we must work across institutional and disciplinary boundaries and continually push these boundaries.

\section{Acknowledgements}

Much of the content of this chapter is revised and updated from my keynote talk as part of the Digital Classicist Berlin seminar programme in October 2013. ${ }^{59}$ Many thanks to the seminar organisers for the kind invitation and also to the editors of this volume for facilitating this publication. Many thanks also to the various reviewers for their helpful and valuable comments.

\section{Notes}

1 Jisc/HEA Open educational resources programme: phase $1<$ http://www. jisc.ac.uk/whatwedo/programmes/elearning/oer.aspx $>$; phase $2<$ http:// www.jisc.ac.uk/whatwedo/programmes/elearning/oer2.aspx $>$; phase 3 $<$ http://www.jisc.ac.uk/whatwedo/programmes/ukoer3.aspx $>$.

${ }^{2}$ With thanks to my colleague Ulrich Tiedau who was grant holder at UCL for this and the DHOER project and first introduced me to the OER movement.

${ }^{3}$ DHOER: <http://www.ucl.ac.uk/dhoer $>$.

${ }^{4}$ CPD4HE: <http://www.ucl.ac.uk/calt/support/cpd4he>; Digital Classicist: $<$ http://www.digitalclassicist.org/>; Stoa Consortium: <http://www.stoa. org/>; OpenLearn: <http://www.open.edu/openlearn/>.

${ }^{5}$ For a very insightful view on the potential possibilities for the transformation of established teaching practice opened up by these resources see Neil Butcher's talk at the 2014 OER Conference in Berlin <http://werkstatt.bpb. de/2013/09/they-must-learn-how-to-learn>.

6 'Learning object' is a debated term and very much context related; for the purpose here I note the Jisc usage: '[...] digital assets which represent an educationally meaningful stand-alone unit' and take this to be small individual resources (presentation slides, reading lists, exercises, discussion topics) that can be used in a class context. <https://www.jisc.ac.uk/guides/ open-educational-resources $>$.

7 See for example Mahony \& Pierazzo 2013; Mahony \& Tiedau 2013.

${ }^{8}$ Mahony, Tiedau \& Sirmons 2012; Tiedau \& Mahony 2011; Mahony 2014; Bodard \& Mahony 2014.

${ }_{9}$ Public Library of Science (PLoS): <www.plos.org/about/open-access >. 
10 UNESCO, Communication and Information <http://www.unesco.org/ new/en/communication-and-information/access-to-knowledge/openeducational-resources/>.

11 'Open access (OA) literature is digital, online, free of charge, and free of most copyright and licensing restrictions.' Suber 2012. See HEA for details about their involvement with the movement <http://www.heacademy.ac.uk/ oer $>$ and more widely the Support Centre for Open Resources in Education (SCORE) <http://www.open.ac.uk/score/publication-type/review-openeducational-resources-oer-movement-achievements-challenges-and-newoppo>.

12 The William and Flora Hewlett Foundation are a major funder of OER grants internationally <http://www.hewlett.org/programs/education/openeducational-resources $>$.

${ }^{13}$ CPD4HE: Open Resources on $\mathrm{HE}$ Teaching and Learning, available: $<$ http://www.ucl.ac.uk/calt/support/cpd4he>; Open educational resources programme - phase 2, available: <http://www.jisc.ac.uk/whatwedo/ programmes/elearning/oer2.aspx>.

${ }^{14}$ Jorum, the Jisc funded UK repository for OERs: <http://www.jorum.ac.uk>; HumBox, a repository set up as one of the pilot projects of OER phase 1 with a focus on the Humanities: <http://humbox.ac.uk>.

${ }^{15}$ UCL Teaching \& Learning Portal: <https://www.ucl.ac.uk/teaching-learning/ technology/oer/OER-repositories $>$.

16 Open Learning Environment for Early Modern Low Countries History: a VirtualDutch Open Educational Resource funded by Jisc and the Higher Education Academy: <http://www.ucl.ac.uk/alternative-languages/OER>.

17 HEFCE: Strategically important and vulnerable subjects (SIVS): <http:// www.hefce.ac.uk/whatwedo/crosscutting/sivs >.

18 Worton 2009.

19 See Mahony, Tiedau \& Sirmons 2012: 175-7.

${ }^{20}$ DHOER: Digital Humanities Open Educational Resources: <http://www. ucl.ac.uk/dhoer $>$.

${ }^{21}$ Note that none of the following search functions are case-sensitive; identical results were obtained when using capitalisation.

${ }^{22}$ This is a collection of 31 images scanned from the holdings of the Roderic Bowen Library at the University of Wales, Trinity Saint David, Lampeter Campus as part of the Jisc/HEA OER Phase 1.

23 The former does contain 'classical' but not 'studies' and neither appear in the latter. Changing the search term to 'classical' returns different results with the former coming second in the list and no sign of the latter. The same search was tested on a variety of machines using Chrome 'incognito' and Firefox 'private window' while logged out of any Google account to check that any prior search history recorded either by Google or the browser was not skewing the results. 
${ }^{24}$ By way of comparison, searching 'classical and studies' (in an attempt at a Boolean search) or locking the words 'classical' and 'studies' together as a single 'string' ('classical studies') returns no results.

${ }^{25}$ Massive Open Online Course (MOOC): see for example the University of London International Programmes hosted on Coursera <http://www. londoninternational.ac.uk/coursera $>$. For more on this and the University of London's aim in using them, see their inaugural report (2013) on their MOOCs <http://www.londoninternational.ac.uk/sites/default/files/ documents/mooc_report-2013.pdf $>$.

${ }^{26}$ MIT OCW allows you to freely download a full course together with all the teaching material in a zip file (primarily XML and PDF files) which when unpacked replicates what would be found online. All this is accompanied by a Creative Commons Attribution-NonCommercial-ShareAlike U3.0 S licence <http://creativecommons.org/licenses/by-nc-sa/3.0/us/deed.en_ US $>$. Coursera is also free at point of use but asks that you sign up and follow the particular course of study. They act as a hosting service for partner institutions for which they charge a fee; for example, see the University of London MOOCs report (2013).

${ }^{27}$ MIT OCW: <http://ocw.mit.edu/>; Coursera: <http://www.coursera. org/>.

28 This is not too unexpected as MIT does not have a Classics department, although they do have one for History <http://ocw.mit.edu/courses/findby-department>.

${ }^{29}$ Of particular note is that these results are significantly different from those obtained in preparation (September 2013) for the talk in Berlin which gave 3,970 hits for 'Classics' and 6,320 for 'Classical Studies' on MIT OCW. Similarly, at that time there were 3,770 hits on MIT for 'Latin', although again almost entirely Latin American studies. Either the available courses have been revised or more likely that the keyword searching has been adjusted in some way during the interim (see <http://hdl.handle.net/11858/00-17800000-0022-D53B-9\#slides $>$ for the slides from Berlin which have screenshots showing the figures).

${ }^{30}$ Again with significantly different results on MIT OCW compared with September 2013 when there were 417; Coursera had only one.

31 Udacity: <http://www.udacity.com/>.

32 edX - "About us": <https://www.edx.org/about-us >. It is not clear from their documentation what the ' $x$ ' denotes other than 'extension' and the forming of the 'xConsortium' made up of the contributing partners.

${ }^{33}$ FutureLearn partners <http://www.futurelearn.com/>.

${ }^{34}$ Digital Classicist wiki $>$ Tools $>$ Educational Resources $<$ http://wiki.digital classicist.org/Educational_Resources $>$.

35 See n. 4, above. With thanks to James Robson et al. at the Open University for help in pointing me to these and clarifying things. 
${ }^{36}$ Open University Classical Studies: <http://www.open.ac.uk/Arts/classicalstudies $>$.

37 Creative Commons, Attribution- NonCommercial- ShareAlike <https:// creativecommons.org/licenses/by-nc-sa/3.0>.

38 Xpert, about: <http://www.nottingham.ac.uk/xpert/about.php >.

39 It cannot, therefore, be fully indexing HumBox and Jorum as would be expected; all DHOER material has been uploaded to HumBox and the metadata for that harvested by Jorum.

${ }^{40}$ Oxford University Podcasts: <http://podcasts.ox.ac.uk/units/faculty-classics $>$.

41 The Stoa Consortium - about this site: <http://www.stoa.org/about>.

${ }^{42}$ Indeed, the Suda On Line has just reached a major milestone with a now complete translation of all the entries <http://www.stoa.org/archives/1998>.

${ }^{43}$ EpiDoc update and release new TEI XML guidelines as they become available; version 8.19 was released on 31/07/2014 <http://sourceforge.net/p/ epidoc/wiki/LatestRelease>.

${ }^{44}$ Ancient World Image Bank <http://isaw.nyu.edu//ancient-world-imagebank>.

${ }^{45}$ Creative Commons Attribution 2.0 Generic (CC BY 2.0) < http://creative commons.org/licenses/by/2.0/deed.en>.

${ }^{46}$ Perseids <http://sites.tufts.edu/perseids $>$.

${ }^{47}$ Iliados $<$ http://iliados.com $>$.

48 Alpheios <http://alpheios.net $>$.

49 Keegan 2008.

${ }^{50}$ McLoughlin 1999.

${ }^{51}$ Altarriba 2002.

52 New Approaches to eLearning in Classics 1 \& 2: the programme and abstracts are at <http://www.nottingham.ac.uk/classics/documents/ classical-association/conference-booklet.pdf $>$.

53 iLatin and eGreek - Ancient Languages and New Technology, February 1, 2014 <http://www.open.ac.uk/Arts/classical-studies/ilatin-egreek.shtml>.

${ }^{54}$ Hestia2 - Digital Pedagogies: <http://hestia.open.ac.uk/digital-pedagogy $>$.

55 As well as direct government support in the USA, grants for OER development and research have been awarded by the Hewlett, Mellon and Gates Foundations; the 12th Annual Open Educational Conference, Vancouver BC, Canada: <http://openedconference.org/2015/>; OER15 <https://oer15. oerconf.org/>; OER14<https://oer14.oerconf.org >.

56 Jisc Open Education <https://www.jisc.ac.uk/rd/projects/open-education $>$.

57 Open Education Working Group: Handbook <http://education.okfn.org/ handbook>.

${ }^{58}$ LinkedUp Project: Linking Web and Data for Education <http://linkedupproject.eu>; Open Education Handbook Booksprint, London September $2013<$ http://education.okfn.org/open-education-handbook-booksprint>.

${ }^{59}$ Video online at <http://hdl.handle.net/11858/00-1780-0000-0022-D53B-9>. 


\section{References}

Altarriba, J. (2002). Bilingualism: Language, memory, and applied issues. In Lonner, Dinnel, Hayes \& Sattler (Eds.), Online Readings in Psychology and Culture (Unit 4, Chapter 4), Center for Cross-Cultural Research, Western Washington University.

Bodard, G. \& Mahony, S. (2014). Open Educational Resources and the Digital Classicist community. Hestia2 Digital Pedagogy: transforming the interface between research and teaching, Open University seminar, London.

Keegan, D. (2008). How Successful Is Mobile Learning? Available from <http:// www.ericsson.com/res/thecompany/docs/programs/the_role_of_mobile_ learning_in_european_education/eclo_ericsson_keegan.pdf>

Mahony, S. (2014). Open Educational Resources and their place in teaching and research for Classics. Classical Association Annual Conference, University of Nottingham.

Mahony, S. \& Pierazzo, E. (2013). Teaching Skills or Teaching Methodology? In Hirsch (Ed.), Digital Humanities Pedagogy: Practices, Principles and Politics, Open Book Publishers, Cambridge.

Mahony, S. \& Tiedau, U. (2013). Should the Digital Humanities be taking a lead in Open Access and Online Teaching Materials? Digital Humanities 2013: Conference Abstracts. University of Nebraska-Lincoln. Available from $<$ http://dh2013.unl.edu/abstracts/ab-283.html $>$.

Mahony, S., Tiedau, U. \& Sirmons, I. (2012). Open access and online teaching materials for digital humanities. In Warwick, Terras \& Nyhan (Eds.) Digital Humanities in Practice. Facet Publishing, London.

McLoughlin, C. (1999). The implications of the research literature on learning styles for the design of instructional material. Australian Journal of Educational Technology, 1999, 15(3): 222-241.

Tiedau, U. \& Mahony, S. (2011). Open Educational Resources for the Digital Humanities. OER11. Open Educational Resources Conference, Manchester.

Suber P. (2012). Open Access, MIT Press. Available from <https://mitpress.mit. edu/sites/default/files/9780262517638_Open_Access_PDF_Version.pdf>

Worton, M. (2009). Review of Modern Foreign Languages provision in higher education in England, HEFCE report. Available from <http://www.ucl. ac.uk/vice-provost/worton/myimages1/worton_report.pdf $>$ 